\title{
Research on the Applicability of Fama-French Five- factor Model in Chinese A-share Market
}

\author{
Yanliang Zhang \\ Shandong University of Finance and Economics \\ Jinan, China
}

\author{
Fanhao Li \\ Shandong University of Finance and Economics \\ Jinan, China
}

\author{
Yue Gong \\ Shandong University of Finance and Economics \\ Jinan, China
}

\begin{abstract}
Chinese securities market is still in the stage of development, Fama-French three-factor model is widely considered to be applicable in Chinese A-share Market, and the explanation ability of Fama-French five-factor model need to be researched. From empirical perspective, this paper takes 495 Shanghai A-share as samples, selected in May 2005 to April 2015 as the research range; the results show that FamaFrench five-factor model is applicable in China stock market, but the explanation ability less than three-factor model. It provides reference for the capital asset pricing model in China.
\end{abstract}

Keywords-capital asset pricing; Fama-French three-factor model; Fama-French five-factor Model

\section{INTRODUCTION}

Since the establishment of Chinese securities market for nearly 30 years, the rapid development rate has brought a lot of investment profit opportunities for domestic investors and has become an important force to promote Chinese economic development. However, the development of Chinese capital market is still immature, and its fluctuations and shocks have a great impact on investors. Therefore, it is very necessary to study the theory of capital pricing. Reasonable pricing can help stock prices fully reflect market information. The main contribution of this paper is to apply the latest theory of capital asset pricing model to Chinese securities market and explore its applicability, and compare it with the three-factor model, which enriches the research in related fields and has certain reference value for Chinese stock market development.

\section{REVIEW OF LITERATURE}

Fama and French (2015) added the two factors of profit and investment to the three-factor asset pricing model to obtain the five-factor pricing model. The empirical results show stronger explanatory power than the three factors, but after adding the profitability factor and investment factor, the value factor becomes a redundant variable, and their explanation is that the two newly added variables contain most of the information of the value factor.
After the Fama-French five-factor model was proposed, foreign scholars extended it to other countries and analyzed the applicability and fit of the model. Chiah M and Chai D etc (2016) used the stock market of Australia from 1982 to 2013 as a research sample and found that the five-factor model can better explain the asset pricing vision than other pricing models, at the same time, they found that unlike the US market value factor HML, which has become redundant, it still has explanatory power after adding new factors. Their findings provide new evidence for the applicability of the five-factor model in the international capital market.

The emerging capital market has become an indispensable part of the international capital market. Taking China as an example, domestic scholars have also been committed to expanding and improving the Fama-French three-factor model to find models that are more suitable for Chinese national conditions. Fan Longzhen, Wang Haitao (2003) Using Fama-Macbeth regression analysis method to analyze the relevant data of the Shanghai stock market from July 1995 to June 2000, analyzing the effect of total market value, circulation market value, price, book to market value ratio, price-earnings ratio and book-to-asset ratio on the stock returns, the results show that the Shanghai stock market has a significant market value, book value to market ratio, price-earnings ratio and stock price effect, he proposed that adding the ratio of the earnings ratio to the three-factor factor model can get better results. Wang Tao (2012) used all the A shares from July 2004 to July 2011 in the Shanghai and Shenzhen stock markets as samples to verify the threefactor model and the extended model of the added $\mathrm{P} / \mathrm{E}$ ratio, and found that the price-earnings ratio factor also has a certain ability to explain the stock returns. After the fivefactor model was put forward, domestic scholars began to test their applicability in China's securities market through empirical analysis, but the current literature is less. Among them, Zhou Luo and Zhang Deli (2016) Through a crosssectional regression analysis of 935 stocks in the Shanghai stock market and found that the five-factor model has a good degree of fit, but the explanatory power is weaker than the US market. Zhao Shengmin, Yan Honglei, and Zhang Kai (2016) conducted an empirical study using the monthly A- 
share returns and financial data for Shanghai and Shenzhen stock markets from January 1995 to December 2014. The results show that the new factor is redundant and the threefactor model is more suitable to Chinese market.

In summary, the current research focus at home and abroad is to verify whether the Fama-French three-factor model or the five-factor model is established. At the same time, it is looking for the theoretical basis of the model so that it is not only the result of statistical data. At the same time, it is not clear whether the five-factor model is applicable in China. The research in this paper can enrich the literature in this field.

\section{THE MOdEL CONSTRUCTION OF THE FAMA-FRENCH FIVE-FACTOR MODEL}

\section{A. Model Design and Construction}

To set up the mathematical expression according to the Fama-French five-factor model as follows:

$$
\underset{+\mathrm{s}_{\mathrm{i}} \mathrm{SMB}_{\mathrm{t}}+\mathrm{h}_{\mathrm{i}} \mathrm{HML}_{\mathrm{t}}+\mathrm{r}_{\mathrm{i}} \mathrm{RMW}_{\mathrm{t}}+\mathrm{a}_{\mathrm{i}}+\mathrm{c}_{\mathrm{i}} \mathrm{CMA}_{\mathrm{t}}+\mathrm{e}_{\mathrm{t}}}{\mathrm{b}_{\mathrm{i}}} \mathrm{MKT}_{\mathrm{t}}
$$

$a_{i}$ is the intercept term that represents the unconditional limited average return of a single stock or portfolio $i ; R_{i}$ is the yield of stock or portfolio $\mathrm{i}, \mathrm{R}_{\mathrm{f}}$ is the risk-free yield, and et is the error term; $R_{i}-R_{f}=$ excess return for a selected stock or portfolio $\mathrm{i} ; \mathrm{MKT}=\mathrm{Rm}-\mathrm{R}_{\mathrm{f}}=$ excess returns for the entire market portfolio.

Among them, the risk-free rate $\mathrm{R}_{\mathrm{f}}$ uses the risk-free rate of return in the Reith financial database. Since the scale and maturity of Chinese bond market have been increasing for a long time, it cannot be used as the risk-free rate of return in the US's capital market.

\section{B. Sample Selection and Data Processing}

This article takes the A-share listed company listed on the Shanghai Stock Exchange as the research object. The time span spans from May 2005 to April 2015. The data comes from the CSMAR database and the RESSET database. In order to make the results more accurate and credible, this article selects monthly data for research, and excludes financial stocks, ST stocks, stocks with negative book to market value ratios, and stocks with missing information.

\section{Construction of Dependent Variable Stock Portfolio}

From 2005 to 2014, according to the company's total market capitalization of stocks on April 30 each year, the stock is divided into five groups from small to large. Since there are 495 sample stocks, each group has 99 stocks, and then each of these five groups will be further divided into five groups according to the ratio of book value to market value, profit margin, and total asset growth at the end of the previous year. This can be used to obtain 3 different combinations of 25 indicators.

On the basis of the above groupings, the monthly excess returns corresponding to the 25 stock portfolios were calculated, and the geometric average of the yields for 120 months from May 2005 to April 2015 was calculated. Through comparative study found: First, for each classification method, the excess return rate of the stock portfolio decreases with the increase in scale, which shows that the scale effect of China's stock market is very obvious. The return of the company portfolio with smaller total market value is higher than that of the company portfolio with large total market capitalization. The rewards are very obvious in all groups.

Secondly, for the Size-B/M portfolio, the excess return rate of the stock portfolio increases with the increase in the book-to-market ratio, which shows that the value effect of the stock market in China is more obvious, and the stock return with a higher book-to-market value is higher than a lower book-to-market ratio.

\section{Construction of Independent Variables}

According to the ranking of the total market value on April 30th each year, the stocks are divided into two groups: small (S) and large (B), and according to the book to market ratio ,the stocks are divided into two groups with low (L) and high $(\mathrm{H})$, according to the profit rate ,the stocks are divided into two groups with weak earnings (W) and strong ability (R) and two groups with low investment level (C) and high (A) according to the growth rate of total assets. Therefore, 12 combinations of SH, SL, SR, SW, SC, SA, BH, BL, BR, BW, $\mathrm{BC}$, and $\mathrm{BA}$ are obtained, and the monthly excess returns of 12 combinations are obtained. Finally, the independent variable is calculated by the following formula:

$$
\begin{gathered}
\mathrm{SMB}= \\
(\mathrm{BH}+\mathrm{BL}+\mathrm{BR}+\mathrm{BW}+\mathrm{BC}+\mathrm{BA}) / 6 \\
\mathrm{HML}=(\mathrm{SH}+\mathrm{BH}) / 2-(\mathrm{SL}+\mathrm{BL}) / 2 \\
\mathrm{RMW}=(\mathrm{BR}+\mathrm{SR}) / 2-(\mathrm{BW}+\mathrm{SW}) / 2 \\
\mathrm{CMA}=(\mathrm{BC}+\mathrm{SC}) / 2-(\mathrm{BA}+\mathrm{SA}) / 2
\end{gathered}
$$

\section{EMPIRICAL ANALYSIS OF THE APPLICABILITY OF FAMA-FRENCH FIVE-FACTOR MODEL}

In order to test the significance of the new two factors, this paper uses the $5 * 5$ method, generating 25 Size-Inv combinations, 25 Size-OP combinations, and 25 Size-B/M combinations, using the Fama-French five-factor model to regression on sample data. Table 1 lists the results of the Size-B/M combination regression. Due to space limitations, other test results are not listed one by one. Interested readers can request from the author. 
TABLE I. OLS REGRESSION RESULTS FOR THE BOOK-TO-MARKET RATIO COMBINATION

\begin{tabular}{|c|c|c|c|c|c|c|c|c|c|c|}
\hline Size-B/M & Low & 2 & 3 & 4 & High & Low & 2 & 3 & 4 & High \\
\hline & & & & & & \multicolumn{5}{|c|}{$T(a)$} \\
\hline Small & 0.004 & 0.003 & $0.011^{* *}$ & 0.004 & $0.010 * *$ & $(0.71)$ & $(0.46)$ & $(2.21)$ & $(0.78)$ & $(1.95)$ \\
\hline 2 & 0.005 & 0.002 & 0.002 & -0.001 & 0.001 & $(1.04)$ & $(0.51)$ & $(0.48)$ & $(-0.12)$ & $(0.30)$ \\
\hline 3 & -0.000 & 0.000 & 0.003 & -0.002 & -0.003 & $(-0.09)$ & $(0.03)$ & $(0.79)$ & $(-0.29)$ & $(-0.80)$ \\
\hline 4 & -0.000 & 0.002 & -0.005 & -0.002 & -0.004 & $(-0.02)$ & $(0.39)$ & $(-1.44)$ & $(-0.46)$ & $(-0.89)$ \\
\hline Big & -0.000 & -0.005 & -0.003 & -0.002 & -0.005 & $(-0.03)$ & $(-1.14)$ & $(-0.76)$ & $(-0.41)$ & $(-1.05)$ \\
\hline \multicolumn{6}{|c|}{$b$} & \multicolumn{5}{|c|}{$t(b)$} \\
\hline Small & 0.838 *** & 0.891 **** & $0.836^{* * * *}$ & $0.891 * * *$ & $0.815 * * *$ & (13.82) & (13.91) & (15.32) & (16.99) & (13.84) \\
\hline 2 & $0.896^{* * * *}$ & $0.833^{* * * *}$ & 0.877 **** & $0.921 * * *$ & 0.877 *** & (15.30) & (16.03) & (16.71) & (16.43) & (15.83) \\
\hline 3 & $0.821 * * *$ & $0.886 * * *$ & $0.875^{* * * *}$ & $0.784 * * * *$ & $0.950 * * *$ & $(15.35)$ & $(14.62)$ & (18.47) & $(11.39)$ & $(20.27)$ \\
\hline 4 & $0.818^{* * * *}$ & 0.884 **** & 0.914 **** & $0.937 * * *$ & $0.969 * * *$ & (13.86) & (14.61) & (17.35) & (19.34) & (18.04) \\
\hline Big & 0.797 *** & 0.930 *** & $1.043^{* * *}$ & $0.960 * * *$ & $0.995 * * *$ & $(14.69)$ & (18.53) & $(20.91)$ & $(16.69)$ & (18.18) \\
\hline \multicolumn{6}{|c|}{$s$} & \multicolumn{5}{|c|}{$t(s)$} \\
\hline Small & $0.947 * * *$ & 0.976 *** & 0.879 *** & $1.163 * * *$ & $0.563 * * *$ & $(6.70)$ & $(6.54)$ & $(6.91)$ & $(9.50)$ & $(4.10)$ \\
\hline 2 & $0.817 * * *$ & 0.819 **** & $0.954 * * *$ & $1.021 * * *$ & $0.990 * * *$ & (5.98) & $(6.76)$ & $(7.79)$ & $(7.81)$ & $(7.66)$ \\
\hline 3 & $0.609 * * *$ & $0.764 * * *$ & $0.766^{* * *}$ & $0.725 * * * *$ & $0.855 * * *$ & $(4.88)$ & $(5.40)$ & $(6.93)$ & $(4.52)$ & $(7.83)$ \\
\hline 4 & 0.498 **** & 0.520 **** & 0.702 **** & $0.782 * * *$ & $0.774 * * * *$ & (3.61) & $(3.69)$ & $(5.72)$ & $(6.92)$ & $(6.18)$ \\
\hline Big & $0.265^{* *}$ & $0.220^{*}$ & -0.027 & 0.090 & $0.263 * *$ & $(2.10)$ & $(1.87)$ & $(-0.23)$ & $(0.67)$ & $(2.06)$ \\
\hline \multicolumn{6}{|c|}{$h$} & \multicolumn{5}{|c|}{$t(h)$} \\
\hline Small & $-0.381 *$ & -0.216 & 0.058 & 0.088 & -0.078 & $(-1.93)$ & $(-1.04)$ & $(0.32)$ & $(0.51)$ & $(-0.41)$ \\
\hline 2 & $-0.620 * *$ & -0.144 & -0.187 & -0.101 & 0.064 & $(-3.25)$ & $(-0.85)$ & $(-1.10)$ & $(-0.55)$ & $(0.35)$ \\
\hline 3 & $-0.671 * *$ & $-0.427 * *$ & $-0.470 * *$ & 0.068 & $0.336^{* *}$ & $(-3.85)$ & $(-2.16)$ & $(-3.05)$ & $(0.30)$ & $(2.20)$ \\
\hline 4 & $-0.832 * *$ & $-0.644 * *$ & $-0.441 * *$ & -0.061 & 0.009 & $(-4.33)$ & $(-3.27)$ & $(-2.57)$ & $(-0.39)$ & $(0.05)$ \\
\hline Big & $-0.752 * *$ & $-0.934 * *$ & $-0.775 * *$ & $0.566 * * *$ & 0.181 & $(-4.26)$ & $(-5.72)$ & $(-4.77)$ & (3.02) & $(1.01)$ \\
\hline \multicolumn{6}{|c|}{$r$} & \multicolumn{5}{|c|}{$t(r)$} \\
\hline Small & $-0.498 * *$ & $-0.739 * *$ & $-0.612 * *$ & $-0.469 * *$ & $-1.030 * *$ & $(-2.24)$ & $(-3.14)$ & $(-3.05)$ & $(-2.43)$ & $(-4.76)$ \\
\hline 2 & $-0.434 * *$ & $-0.504 * *$ & -0.167 & $-0.600 * *$ & $-0.368^{*}$ & $(-2.02)$ & $(-2.64)$ & $(-0.87)$ & $(-2.91)$ & $(-1.81)$ \\
\hline 3 & -0.305 & $-0.443 * *$ & $-0.296^{*}$ & $-0.585^{* *}$ & $-0.382 * *$ & $(-1.55)$ & $(-1.99)$ & $(-1.70)$ & $(-2.31)$ & $(-2.22)$ \\
\hline 4 & -0.258 & $\begin{array}{l}-0.379 * \\
\end{array}$ & $-0.378^{*}$ & $-0.412 * *$ & -0.205 & $(-1.19)$ & $(-1.71)$ & $(-1.95)$ & $(-2.32)$ & $(-1.04)$ \\
\hline Big & 0.035 & 0.118 & 0.048 & $0.629 * * *$ & 0.012 & $(0.18)$ & $(0.64)$ & $(0.26)$ & $(2.98)$ & $(0.06)$ \\
\hline & \multicolumn{5}{|c|}{$t(c)$} \\
\hline Small & $0.802^{* * * *}$ & $0.349 * *$ & 0.158 & $0.343^{*}$ & 0.235 & $(4.18)$ & $(1.72)$ & $(0.92)$ & $(2.06)$ & $(1.26)$ \\
\hline 2 & $0.388 * *$ & 0.101 & $0.432^{* * *}$ & 0.169 & $0.381 * *$ & $(2.09)$ & $(0.61)$ & $(2.60)$ & $(0.95)$ & $(2.17)$ \\
\hline 3 & $0.312 *$ & $0.384 * *$ & $0.353^{* *}$ & $-0.769 * *$ & 0.077 & $(1.84)$ & $(2.00)$ & $(2.35)$ & $(-3.53)$ & $(0.52)$ \\
\hline 4 & 0.257 & 0.235 & $0.426^{* *}$ & $0.288^{*}$ & $0.844 * * *$ & $(1.37)$ & $(1.22)$ & $(2.55)$ & $(1.87)$ & $(4.96)$ \\
\hline Big & $0.339^{*}$ & 0.613 *** & 0.218 & $0.318^{*}$ & $0.525^{* * * *}$ & (1.97) & $(3.86)$ & $(1.38)$ & $(1.75)$ & $(3.03)$ \\
\hline
\end{tabular}

This article judges the applicability of the five-factor model in Chinese stock market based on two main reasons: (1) GRS test. The smaller the value of the GRS statistic is, the less benefit the factor can explain in the model, and the better the model's ability to interpret. Specifically, it is mainly to see how the size of the intercepted item ai is after the regression, and whether the joint is 0 . According to the $\mathrm{t}$ statistic of the intercept term ai,If ai rejects the null hypothesis ai $=0, \forall i, i=1,2, \ldots, 25$, this indicates that the FamaFrench five-factor model may be applicable in the Chinese A-share market; on the contrary, the model is not applicable in the Chinese A-share market. (2) Factor regression coefficient significance test.

By analyzing "Table I", we have the following conclusions:

- For the intercept term $\mathrm{a}_{\mathrm{i}}$, only 2 dates are significantly not 0 . Overall, $a_{i}$ is not significant. According to the GRS test, the original hypothesis is rejected as $\mathrm{a}_{\mathrm{i}}=0$, $\forall \mathrm{i}, \mathrm{i}=1,2, \ldots, 25$, which in accordance with FamaFrench's conclusion, so the Fama-French's five-factor model may be applicable in Chinese A-share market.
- The regression coefficient of market risk factors is very significant, and stable at about 0.9 , indicating that market factors still capture most of the crosssectional returns of stocks.

- There are 23 and the coefficients shows a tendency of becoming smaller during the process of changing from small market value to large market value, which shows that the scale effect of Chinese stock market is very obvious, and the coefficient s did not show a clear trend in the process of changing from the low book to market value ratio to a high book to market value ratio.

- There are 13 coefficients of factor HML that are significantly non-zero factor. The regression coefficient of the low book to market ratio is basically negative, and the coefficient basically shows an upward trend. The value effect is obvious.

- There are 17 coefficients of investment factor RMW that are significantly non-zero factor, indicating that the profit factor RMW is significant overall, and the coefficient of the profit factor RMW cannot reject the null hypothesis that the benchmark portfolio is 
mainly present in the large Scale or low book to market value ratio.

- There are 17 coefficients of investment factor RMW that are significantly non-zero factor, indicating that the investment factor CMA is significant in general, and its explanatory capacity has little difference between the scale and the book to market value ratio.

The difference between the portfolio of stocks classified by profit rate and the portfolio classified by total asset growth rate is that the non-zero number of factors of the book to market value ratio factor HML is significantly less and the value effect is not obvious.

In order to better verify the adaptability of the five-factor model in Chinese stock market and to compare it with the three-factor model's explanatory power, this paper uses the three-factor model to simultaneously perform different combinations of the same data for regression. This paper is no longer listed in this article. Through comparative analysis, the regression coefficient of the three-factor model market risk factor is very significant. Its value is larger than the fivefactor model. It shows that the market factor is more capable of explaining the cross-section earnings of stocks than the five-factor model. After adding new factors, the proportion of system risk in the total risk decreases; $23 \mathrm{SMB}$ factor coefficients are not significantly 0 , the scale effect is significant, and the coefficient is larger than the five-factor model, indicating that the "small companies effect" in the Chinese stock market has weakened in the five-factor model; there are $17 \mathrm{HML}$ factor coefficients that are significantly non-zero. As the book-to-market ratio increases, the regression coefficient increases, indicating that the book-tomarket ratio factor can explain the changes of the return rate of Chinese stock market, and this factor is no longer significant in the five-factor model, which is considered "redundant" compared to the RMW factor and the CMA factor.

In addition, we also compared the adjusted R2. We found that the average adjusted R2 for the three-factor model was $87.02 \%$, indicating that $87.02 \%$ of the Chinese stock market's return can be explained. The average adjusted R2 of the five-factor model is $78.05 \%$, although smaller than the three-factor model, it still accounts for $78.05 \%$ of the total excess return and has a good fit.

\section{CONCLUSION}

This article uses monthly return rate data from May 2005 to April 2015 in Shanghai Stock Market as a sample of empirical research. Each investment portfolio is constructed based on Size-Inv, Size-OP and Size-B/M. After empirical analysis, this paper draws the following conclusions:

- The five-factor model can explain the changes in stock cross-section returns and is applicable to Chinese stock market. However, compared with the three-factor model, the explanatory power has declined, which is different from the conclusion drawn by Fama-French using US data;
- The SMB factor is very significant, indicating that the scale effect in China is significant;

- The HML factor is not significant overall. Compared with the three-factor model, its explanatory function is weakened. Show that the stock market in Chinese stock market does not show a significant phenomenon in which the company with high $\mathrm{B} / \mathrm{M}$ has higher stock return than the company with low $\mathrm{B} / \mathrm{M}$. However, existing studies have shown that risk premiums for value factors can basically be explained by other factors, especially for profitable factors and investment factors. If you want to better estimate the risk premium of each factor, you can use value factors to regression for the market, the scale, the profit, and the investment factors, adding the intercepts and errors, constructing orthogonal HML factor (HMLO), replacing HML with HMLO, and adding five-factor model;

- The RMW factor's coefficient is more significant, indicating that the stock market in our country has a profitability effect, that's to say, companies with strong profitability have higher stock returns than those with weak profitability.

- The coefficient of CMA factor is generally significant, which shows that there is an investment effect in Chinese stock market, companies with lower investment levels have higher stock returns than companies with high investment levels.

In summary, the Fama-French five-factor model is generally applicable to Chinese A-share market, but the explanatory power is not as good as the three-factor model. Newly added profitability factors and investment factors can explain the stock returns, and the value factor is no longer significant.

\section{ACKNOWLEDGEMENT}

This is a phase achievement of China Ministry of Education of Humanities and Social Sciences project "Comparative study about BRICS stock market growth capacity 11YJEGJW001".

\section{REFERENCES}

[1] Chiah M, Chai D, Zhong A, Li S.A Better Model? An Empirical Investigation of the Fama-French Five-factor Model in Australia.International Review of Finance,2016.

[2] Zhou W, Li L.A New Fama-French 5-Factor Model Based on SSAEPD Error and GARCH-Type Volatility.Journal of Mathematical Finance,2016. Vol.06 No.05.p711-727.

[3] CC Martins, WE Jr. Pricing Assets with Fama and French 5-Factor Model: a Brazilian market novelty. Encontro Brasileiro de Financas.2015.No.07.p1-13.

[4] Fan Longzhen, Wang Haitao, Research on the Factors of Stock Yield in Shanghai Stock Market, Journal of Management Science, June 2003, p60-67.

[5] Wang Tao, Applicability of Fama-French three-factor model and its added P/E factor model in China's stock market, Southwest University of Finance and Economics dissertation, June 2012. 
[6] Zhou Luo, Zhang Deli, An Empirical Study on the Effectiveness of China's Stock Market: Based on the Fama-French Five-Factor Model, Business Manager, May 2016, p16.

[7] Zhao Shengmin, Yan Honglei, Zhang Kai, Is the Fama-French FiveFactor Model Superior to the Three-Factor Model? Empirical Evidence from the Chinese A-Share Market, Nankai Economic Research, February 2016,p 41-59. 